\title{
Association of the p53 codon 72 polymorphism with clinicopathological characteristics of colorectal cancer through mRNA analysis
}

\author{
LIGIA PETROLINI DE OLIVEIRA ${ }^{1}$, IGNACIO LÓPEZ ${ }^{2}$, \\ ERIKA MARIA MONTEIRO DOS SANTOS ${ }^{1}$, PAULA TUCCI ${ }^{2}$, \\ MÓNICA MARÍN ${ }^{2}$, FERNANDO AUGUSTO SOARES ${ }^{1}$, \\ BENEDITO MAURO ROSSI ${ }^{1}$ and RENATA DE ALMEIDA COUDRY ${ }^{1}$
}

\author{
${ }^{1}$ Department of Anatomic Pathology, International Center for Research (CIPE) in Oncology, \\ A.C. Camargo Cancer Center, São Paulo, SP, CEP 01508-010, Brazil; ${ }^{2}$ Department of Biochemistry, \\ Faculty of Science, Universidad de la República, Montevideo CEP 11400, Uruguay
}

Received September 26, 2013; Accepted October 18, 2013

DOI: $10.3892 /$ or.2013.2940

\begin{abstract}
TP53 represents a suitable candidate for a colorectal cancer susceptibility locus. The polymorphism in the p53 72nd codon involves a proline to arginine substitution, leading to changes in gene transcription activity, interaction with other proteins and modulation of apoptosis. Studies evaluating the association between this polymorphism and colorectal cancer (CRC) have shown inconsistent results, and none have evaluated the mRNA status of TP53. The aim of the present study was to evaluate the association between this SNP expression at the mRNA level in CRC samples and patient clinicopathological variables and prognosis, p53 protein expression and TP53 mutation. This is the first report to describe the mRNA expression of p53 codon 72 alleles in CRC. We evaluated 101 non-related patients with CRC treated at the A.C. Camargo Cancer Center in Brazil. RNA was isolated from frozen tumor tissues using a TRIzol-based protocol. The polymorphism was detected using RT-PCR followed by Sanger sequencing. Associations were analyzed using Pearson's Chi-square or Fisher's exact tests, logistic regression and Cox. This polymorphism was significantly associated with clinicopathological variables related to increased tumor aggressiveness. The expression of Arg72 (OR, 3.83; CI 1.02-14.35; $\mathrm{P}=0.046$ ) and the TNM stage (OR, 7.15; CI 1.45-35.29; $\mathrm{P}=0.016)$ were found to be independent predictors for recurrence. These data suggest that the mRNA expression of the Pro72 allele is asso-
\end{abstract}

Correspondence to: Dr Ligia Petrolini de Oliveira, Department of Anatomic Pathology, CIPE in Oncology, A.C. Camargo Cancer Center, Taguá St. 404, 1st Floor, São Paulo, SP, CEP 01508-010, Brazil

E-mail: ligia.petrolini@gmail.com

Key words: colorectal cancer, TP53 polymorphism, mRNA analysis ciated with less favorable tumor features. The allele frequency of the p53 Pro72 was 0.26 . The analysis of mRNA is important to determine the specific contribution of the allele expressed. These results suggest that this polymorphism may play a role in CRC.

\section{Introduction}

Colorectal cancer (CRC) is the third most common cancer type in men and women worldwide. CRC is thought to result from an interaction between environmental and genetic factors (1).

Currently, functional variation of DNA repair and cell cycle control-related genes in the presence of carcinogen-mediated cell damage is believed to be a mechanism for explaining inter-individual variation in CRC susceptibility (1).

Analysis of phenotype concordance in monozygotic twin CRC cases suggest that inherited susceptibility underlies $35 \%$ of all CRCs. However, only $6 \%$ of CRCs occur in the context of a known high-penetrance cancer predisposition syndrome, such as familial adenomatous polyposis or Lynch syndrome $(2,3)$. Therefore, most of the genetic risks for CRC remain unknown (4).

Fearon and Vogelstein (5) proposed a model for the development of CRC whereby colorectal carcinoma arises and progresses through histological stages due to an accumulation of genetic and epigenetic changes. A particular stage of progression of late adenoma to adenocarcinoma involves mutations in TP53. p53 regulates many cellular functions including cell cycle progression, DNA repair, senescence, apoptosis and cellular metabolism (6). In normal cells, the expression level of p53 is extremely low. However, p53 protein levels increase in response to various stress signals, such as DNA damaging agents, oxidative stress, amino acid depletion and temperature change (7).

In addition to the gene mutation, which represent the most common TP53 genetic alteration, multiple single nucleotide polymorphisms (SNPs) have been identified in this gene. However, the relevance of the majority of the SNPs remains 
unclear. The p53 codon 72 SNP (rs1042522), which is located in exon 4 within the p53 transactivation domain in a prolinerich region, results in the expression of either a proline or an arginine due to a nucleotide substitution of the second base in the codon (CCC>CGC), thus, changing from an amino acid with a non-polar aliphatic side chain to an amino acid with a positively charged basic side chain (1).

Several lines of evidence suggest that the resulting two alleles confer different properties to the p53 protein. These p53 variants are not biochemically equivalent, since they show different transcriptional regulation activities, interactions with p73 (a homologue of p53) and degradation rates mediated by the proteasome (8). The allele with proline (Pro72) is considered the wild-type one (9), and it appears less efficient than the allele with arginine (Arg72) at suppression of cell transformation and induction of apoptosis (10). Structural and functional features of p53 might be useful as a molecular prognostic marker (11).

An association between the genotyped p53 codon 72 SNP and human cancer risk has been reported in breast $(12,13)$, gastric $(14,15)$, thyroid $(16,17)$, lung $(18,19)$, vulval $(20)$ and bladder cancers $(21,22)$. However, this SNP does not appear to affect the risk of cervical $(23,24)$, prostate $(25,26)$ and endometrial cancers $(27,28)$ and head and neck squamous cell carcinomas $(29,30)$.

Previous studies have shown that the p53 codon 72 SNP is associated with the risk of $\mathrm{CRC}$ or its precursor lesion adenoma (8,31-36), while others have reported discordant results $(37,38)$. The p53 codon 72 SNP was not found to be associated with the alteration of colorectal cancer risk in a meta-analysis with 20 case-control studies (1).

Mammano et al (8) demonstrated that the genotyped p53 codon 72 SNP is associated with a higher risk of CRC and with more advanced and undifferentiated tumors, suggesting that this SNP may play a role in the progression of CRC.

Most epidemiological studies have evaluated the genotypes of polymorphic genes, searching for alterations in cancer risk. However, it is imperative to evaluate which allele is expressed in the tumor as there may be preferential expression of a specific allele in heterozygotes, which may explain the discordance data related to association of p53 codon 72 SNP with CRC. Moreover, evaluation of the association of the expression of this SNP with patient clinicopathological variables and prognosis can provide relevant data not previously identified.

In order to shed light on the role of this SNP in CRC, we conducted a p53 codon 72 SNP expression analysis searching for associations with p53 protein expression, TP53 mutations, patient clinicopathological variables and prognosis.

\section{Materials and methods}

Study population. We examined mRNA from 101 patients with sporadic origin colorectal tumors who were treated at the Hospital A.C. Camargo (São Paulo, Brazil) and who underwent surgical resection for colorectal adenocarcinoma between 1992 and 2006. Individuals fulfilling any familial syndrome clinical criteria or with inflammatory bowel diseases and those treated with preoperative chemoradiotherapy were excluded from the present study which was reviewed and approved by a duly appointed ethics committee (1042/08).
Clinicopathological data. All clinical data were collected from patient reports, and pathological data of the CRC cases were systematically evaluated by an experienced gastrointestinal pathologist (R.A.C.). The data collected include gender, age at diagnosis, smoking habit (yes or no), CRC location, histological grade, TNM stage (UICC/AJCC), dirty necrosis, desmoplasia, Crohn's-like lymphocytes, infiltrating lymphocytes, vascular and lymphatic invasion, budding, tumor border pattern of growth (expanding or infiltrating), tumor recurrence, use of post-chemoradiotherapy (radiotherapy only for rectal tumors) and follow-up time. Tumor budding was defined as an isolated single cancer cell or a cluster composed of fewer than 5 cancer cells observed in the stroma of the actively invasive area (39).

Immunohistochemistry. The expression status of p53 was evaluated using immunohistochemistry (IHC) technique. IHC staining was performed on 3- $\mu \mathrm{m}$ formalin paraffin-embedded (FFPE) tissues. The reactions were performed using a p53 monoclonal antibody (DO7 clone, 1:100 dilution; Dako, Glostrup, Denmark) and a polymer-based detection system (Advance HRP Link Polymer amplification system; Dako). Positive staining was defined as an unequivocal nuclear staining of neoplastic cells. The percentage of positively stained neoplastic cells was quantified. A tumor was considered positive when $>20 \%$ of its cells were stained.

RNA extraction. Fresh samples were matched with FFPE tissues used for IHC. Total RNA was extracted from manually microdissected frozen tissues with at least $70 \%$ of tumor cells (10-100 mg) by homogenizing each tissue sample using Precellys equipment (Bertin Technologies, Villeurbanne, France) in $1 \mathrm{ml}$ of TRIzol reagent according to the manufacturer's protocol (Invitrogen, Carlsbad, CA, USA). RNA integrity was assessed using an Agilent 2100 Bioanalyzer (Agilent Technologies, Foster City, CA, USA), and RNA was stored at $-80^{\circ} \mathrm{C}$ prior to use.

$R T-P C R$. Total mRNA was employed to synthesize cDNA for TP53 allele expression and mutation analyses using a High Capacity cDNA reverse transcription kit (Applied Biosystems, Foster City, CA, USA). The TP53 transcript was amplified as two overlapping fragments, from exon 2 to 6 and from exon 6 to 11 , covering the entire coding region. PCR was performed in $25-\mu 1$ reactions containing $20 \mathrm{ng}$ of template DNA, $1.5 \mathrm{mM}$ $\mathrm{MgCl}_{2}, 0.2 \mathrm{mM} \mathrm{dNTP}, 0.3 \mu \mathrm{M}$ of forward and reverse primers and 1.5 U of Platinum ${ }^{\circledR}$ Taq Polymerase (Invitrogen). PCR products were analyzed on an agarose gel containing SYBR Safe (Invitrogen). PCR primers are described in Table I.

Sequencing analysis. Samples were screened for mutations over the entire coding region of TP53 and for the presence of polymorphic variants at codon 72 . ExoSAP-IT (1 $\mu$ l, USB; Affymetrix, Cleveland, OH, USA) was used to purify $7 \mu \mathrm{l}$ of the PCR product. Sequencing reactions were performed using the Big Dye Terminator v3.1 Cycle sequencing kit (Applied Biosystems) with specific primers that overlapped the region amplified (Table I) and an ABI PRISM 3730xl Automatic Genetic analyzer (Applied Biosystems), according to the manufacturer's recommendations. 
Table I. Amplification and sequencing primers.

\begin{tabular}{lllc}
\hline Use & \multicolumn{1}{c}{ Primer } & \multicolumn{1}{c}{ Sequence } & Amplicon (bp) \\
\hline PCR fragment 1 & E2ForE RNAm & GACGGTGACACGCTTCCCTG & 708 \\
& E6RevE RNAm & CACCACCACACTATGTCG & 645 \\
PCR fragment 2 & E6ForE RNAm & CCTCAGCATCTTATCCGAG & \\
& E11RevE RNAm & AGGCTGTCAGTGGGGAAC & 654 \\
Sequencing fragment 1 & E2ForI RNAm & CAGCCAGACTGCCTTCCGGGTC & 604 \\
& E6RevI RNAm & CTGTCATCCAAATACTCCACACG & \\
Sequencing fragment 2 & E6ForI RNAm & GGAAATTTGCGTGTGGAG & \\
& E11RevI RNAm & CAAGAAGTGGAGAATGTC & \\
\hline
\end{tabular}

The TP53 polymorphic and mutation status was analyzed using CLC Main Workbench software (CLCbio version 4.6) with p53 NM_000546 reference sequence. Allele expression was determined using electropherogram data from the sequencing analysis. Double peaks of $\mathrm{C}$ and $\mathrm{G}$ nucleotides were considered to indicate heterozygosity.

Statistical analysis. To test the distribution of genotypes and the relationship between the p53 codon 72 SNP and clinical variables, data were analyzed using the 2-sided Pearson's Chi-square or Fisher's exact tests in the SPSS v17.0 program (SPSS, Inc., Chicago, IL, USA). A P $<0.05$ was considered to indicate a statistically significant result.

To identify the variables associated with recurrence, univariate analysis was performed. Variables with $\mathrm{P}<0.20$ were selected for multiple logistic regression model. In this model we considered variables with $\mathrm{P}<0.05$ and present the $\mathrm{OR}$ and the 95\% CI. To determine the variables associated with survival, univariate analysis was performed using the Kaplan-Meier and $\log$ rank test. Variables with $\mathrm{P}<0.20$ were selected for the Cox proportional hazards regression model and the OR and 95\% CI are presented. An $\alpha$ error of $5 \%$ was considered.

\section{Results}

Clinicopathological characteristics. The present study was performed using samples from 101 patients consisting of 49 men and 52 women with a mean age of 62.4 years (median age 63 years; age range $27-88$ years). There were $52(51.5 \%)$ tumors with negative and 49 (48.5\%) with positive p53-protein nuclear accumulation. The tumor was located in the proximal colon in 36 cases (35.6\%), in the distal colon in 42 cases $(41.6 \%)$ and in the rectum in 23 cases (22.8\%). Regarding the histological grade, $9(8.9 \%)$ were well differentiated, $80(79.2 \%)$ were moderately differentiated and $12(11.9 \%)$ were poorly differentiated. Based on TNM staging criteria, 20 (19.8\%) tumors were stage I, $34(33.7 \%)$ were stage II, $26(25.7 \%)$ were stage III and 21 (20.8\%) were stage IV; 58 (57.4\%) tumors were N0, 21 (20.8\%) were N1 and 22 (21.8\%) were N2; and 80 (79.2\%) tumors were M0 and 21 (20.8\%) were M1 (Table II).

Allelic expression associations. All significant associations are shown in Fig. 1. The expression allelic frequencies were
0.26 for Pro72 and 0.74 for Arg72. With regard to allele expression, $66.4 \%(\mathrm{n}=67)$ of individuals were homozygote for Arg72, $15.8 \%(\mathrm{n}=16)$ were heterozygote and $17.8 \%(\mathrm{n}=18)$ were homozygote for Pro72. The analysis also considered the presence of expression of the Arg72 allele: 83 samples (82.2\%) expressed Arg72 and 18 (17.8\%) did not express it. When Arg72 allele expression was correlated with gender, we found that among the CRC tissues from women, 90.4\% expressed Arg72 (at least one allele) and $72.2 \%$ of the CRC tissues from men expressed Pro72 exclusively $(\mathrm{P}=0.037)$. Of the declared smokers, $64.3 \%$ were men.

Correlations between the alleles and the IHC-derived p53 monoclonal antibody staining revealed that the presence of either the Pro72 or Agr72 allele did not affect protein expression. However, the presence of both alleles was associated with normal cellular conditions since $81.3 \%$ of the heterozygotes showed the normal absence of expression of the p53 protein $(\mathrm{P}=0.034)$.

The association between the SNP and tumor stage revealed that $94.4 \%$ of those patients not expressing the Arg72 allele presented tumors with $\mathrm{T} 3$ and $\mathrm{T} 4$ stages, whereas $95.8 \%$ of the tumors in $\mathrm{T} 1$ and $\mathrm{T} 2$ stages were $\operatorname{Arg} 72$ expressers $(\mathrm{P}=0.064)$.

Correlations between the polymorphism and the tumor characteristics showed that the pattern border of tumor growth varied with the allele expressed. An infiltrating border of tumor growth was present in $88.9 \%$ of those tumors not expressing the Arg72 allele, and among all expanding-border tumors, 93.8\% expressed $\operatorname{Arg} 72(\mathrm{P}=0.05)$.

Another finding from the present study was the relationship between tumor recurrence and this SNP since $93.8 \%$ of the Arg72-exclusive expresser tumors did not show tumor recurrence $(\mathrm{P}=0.008)$. Similarly, $91.3 \%$ of those tumors with $\operatorname{Arg} 72$ expression did not show recurrence $(\mathrm{P}=0.013)$. The average time for tumor recurrence was 17 months post surgery.

Further analysis showed a statistically significant relationship between the p53 codon 72 SNP and the use of postoperative adjuvant chemoradiotherapy. Of the tumors expressing Pro72 exclusively, $82.4 \%$ of individuals underwent some type of post-chemoradiotherapy $(\mathrm{P}=0.002)$. Of those who did not receive post-chemoradiotherapy, $78.8 \%$ of the tumors expressed Arg72 exclusively ( $\mathrm{P}=0.005)$.

The present study did not evidence significant difference between this SNP and the relative CRC-free survival rates. 


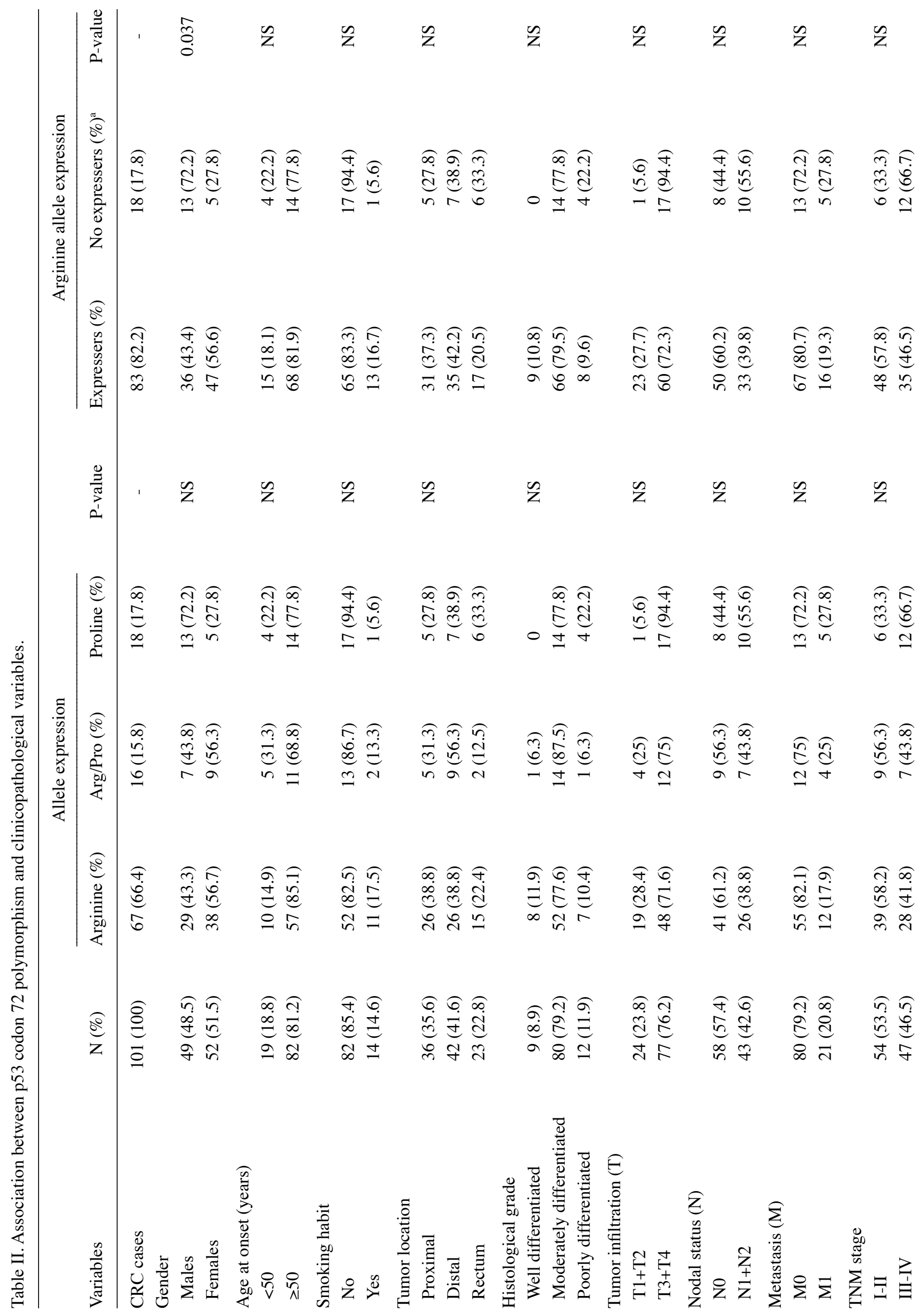




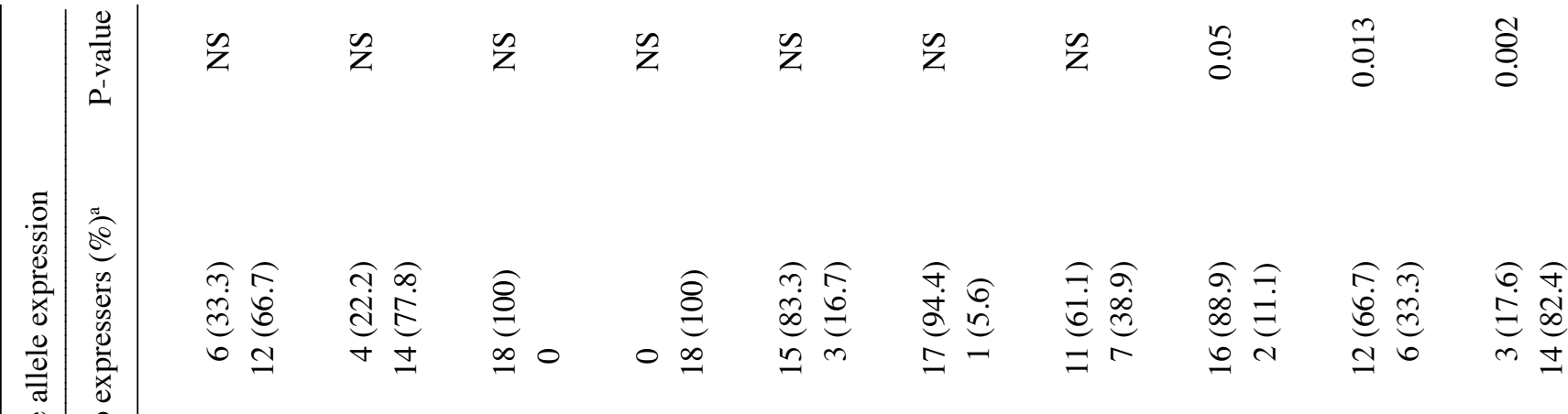

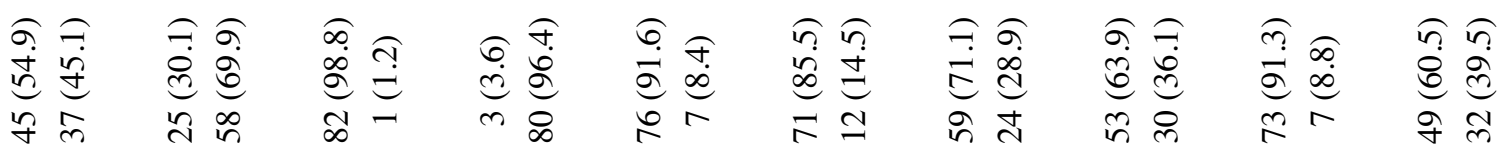

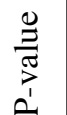

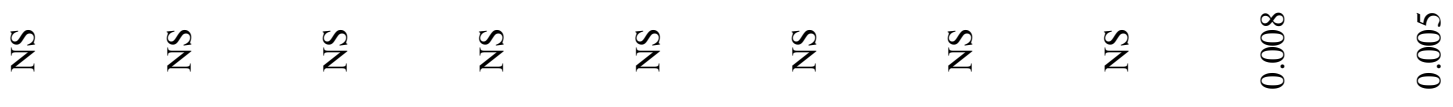

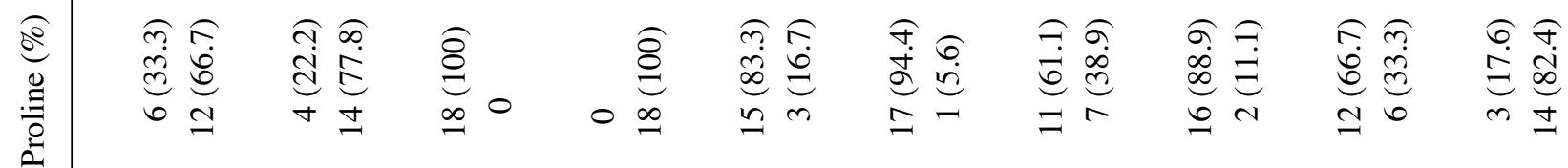

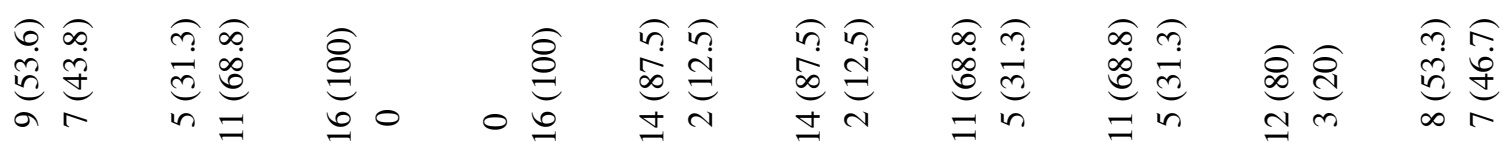

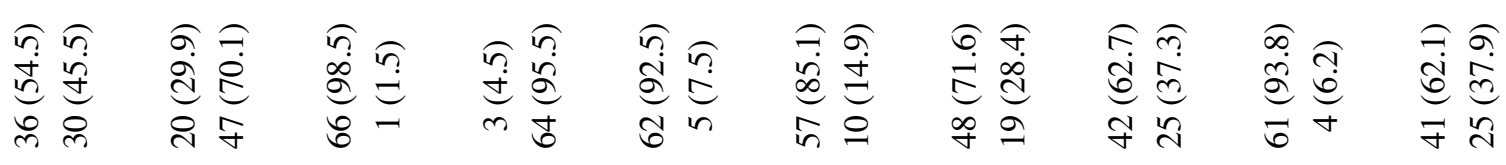

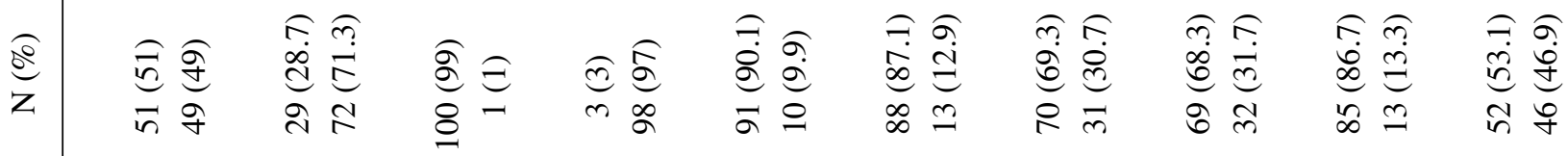

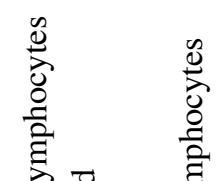

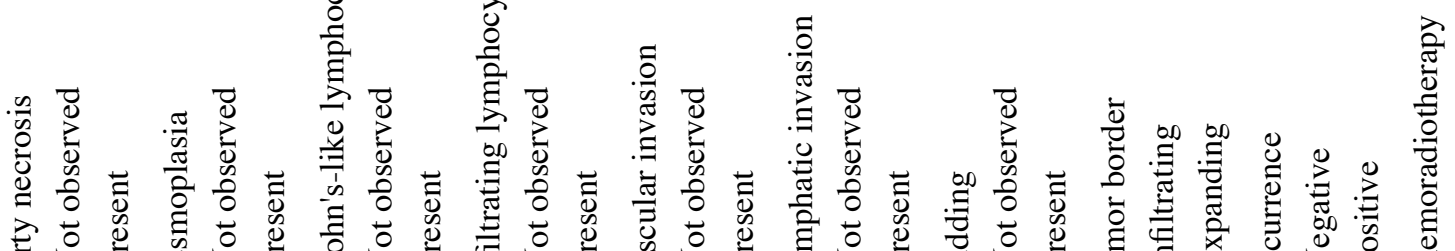

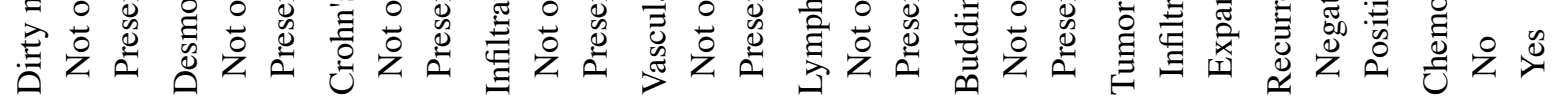


Table III. Multivariate analysis.

\begin{tabular}{lccc}
\hline Variables & OR & CI 95\% & P-value \\
\hline $\begin{array}{l}\text { Survival } \\
\text { TNM stages } \\
\text { I-II }\end{array}$ & 1 & $1.84-10.43$ & 0.001 \\
III-IV & 4.38 & & \\
Perineural invasion & & & \\
$\quad$ Not observed & 1 & $1.26-8.19$ & 0.014 \\
$\quad$ Observed & 3.21 & & \\
Recurrence & & & \\
Arg 72 & & & \\
$\quad$ Expressers & 1 & $1.02-14.35$ & 0.046 \\
No expressers & 3.83 & & \\
TNM stages & & & \\
I-II & 1 & $1.45-35.29$ & 0.016 \\
III-IV & 7.15 & & \\
\hline
\end{tabular}

In the Cox proportional survival model, the independent variables were TNM stage (TNM I-II and III-IV; OR, 4.38; CI 1.84-10.43; $\mathrm{P}=0.001)$ and perineural invasion (OR, 3.21; CI 1.26-8.19; $\mathrm{P}=0.014$ ) (Table III).

In the multiple logistic regression model, the variables that were independent predictors for recurrence were the expression of Arg72 allele (OR 3.83; CI 1.02-14.35; $\mathrm{P}=0.046$ ) and the TNM stage (TNM I-II and III-IV; OR, 7.15; CI 1.45-35.29; $\mathrm{P}=0.016$ ) (Table III). This model explained $24.5 \%$ of the variation of recurrence.

Mutation analysis. We also evaluated the mutation status of the TP53 gene in the CRC samples, published in detail (40). Relative to the alleles expressed, pathogenic mutations were detected in $72.2 \%(n=13)$ of the Pro72-exclusive expressers, in $18.8 \%(n=3)$ of the heterozygotes and in $58.2 \%(n=39)$ of the Arg72-exclusive expressers $(\mathrm{P}=0.004)$. Detailed analyses revealed that among the tumors showing no mutations, $89.1 \%$ were $\operatorname{Arg} 72$ expressers.

\section{Discussion}

$m R N A$ analysis. Genome-wide association studies (GWAS) assaying hundreds of thousands of SNPs have successfully identified a large number of genetic variants associated with complex traits, but each of those variant often confers only a modest increase in risk. One consequence of these small effects is that even combined, these discoveries only explain a small proportion of the entire genetic contribution to risk of disease, thus, leading to the 'missing heritability' question (41).

Many reasons for the missing heritability have been discussed $(42,43)$. Complex patterns of inheritance $(44)$, epigenetic modifications of the genome, common copy-number variants (CNVs) (45), analysis of gene-environment and genegene interactions (epistasis) (46) and the recently proposed 'synthetic association' signals created by rare variants in 

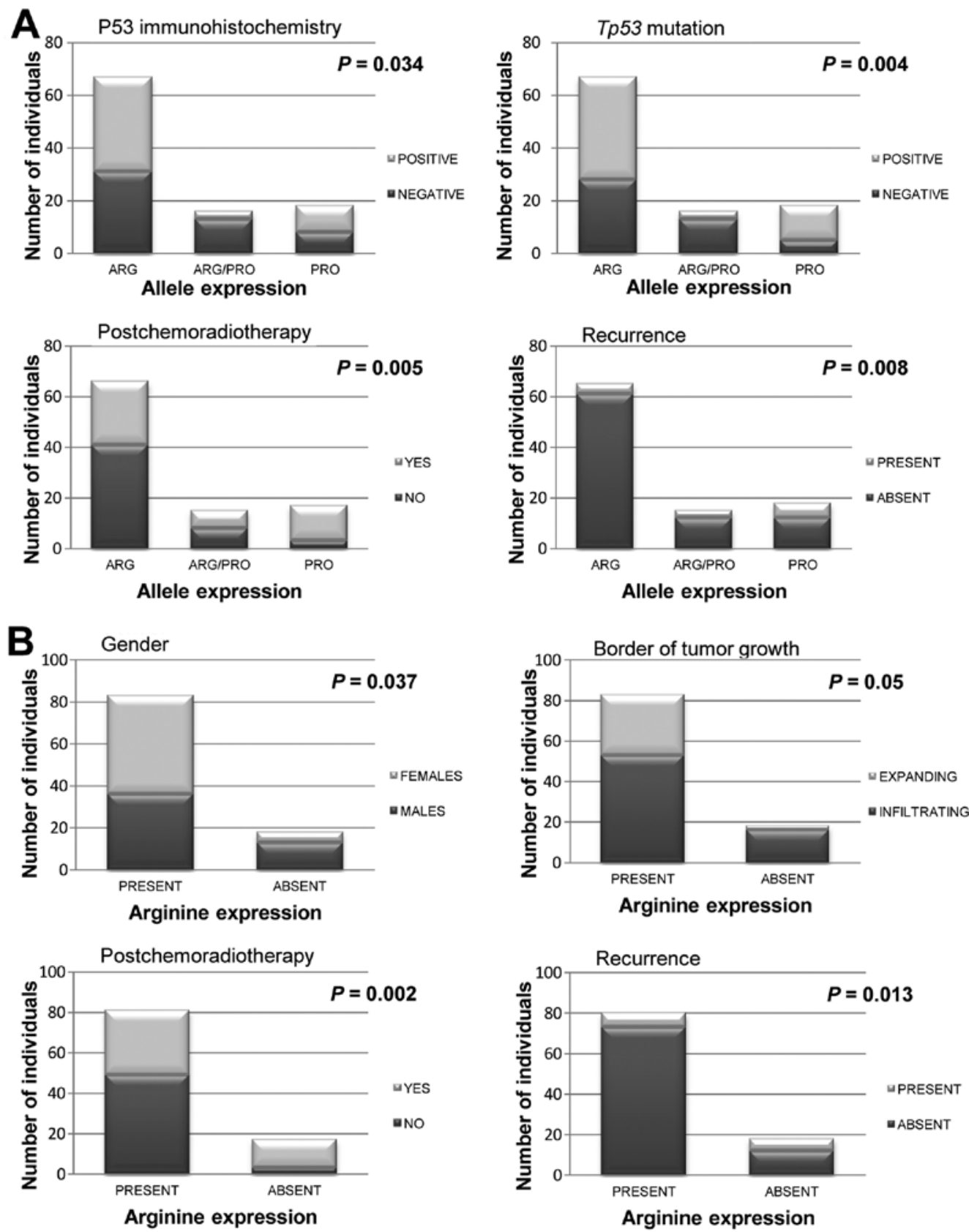

Figure 1. Significant associations between p53 codon 72 SNP and clinicopathological variables. (A) Associations related to genotype expressed by the tumor. (B) Associations relative to the presence of Arg72 allele expression.

GWAS (47) can contribute to the missing heritability. However, we propose that there may be differences in the expression of different polymorphic alleles in large heterozygote populations that may explain cancer behavior and that the real associations can be missed looking only for genomic alterations.

Studies have shown that variations exist in the relative allelic expression levels of specific genes in heterozygotes that contribute to phenotypic variation between individuals. (48-53). Monoallelic expression with random choice between paternal and maternal alleles has also been shown to affect hundreds of autosomal genes and, thus, contribute to individual cell variability (54).

The results presented in the present study highlight a major limitation in comparing our results with other reports since the majority of studies looking for relationships between poly- morphisms and CRC examine the genotype of the individuals rather than the allele expressed in tumors. Siddique et al (13) showed that breast tumors from heterozygous Chinese women preferentially expressed the Pro72 allele compared to health ones. Thus, the expression status of the p53 alleles in tumors, rather than the genotype, may be a determining factor to better understand the tumor process.

Pro72 vs. Arg72. The p53 codon 72 SNP occurs in the proline-rich domain of $\mathrm{p} 53$, which is necessary for the protein to fully induce apoptosis. The polymorphic forms of the p53 protein result in marked alterations in the protein primary structure (55). Data from Marin et al (10) suggest that the Pro72 allele displays decreased efficiency in binding p73 and consequently inhibits p73-dependent apoptosis in p53 mutants. 
Dumont et al (56) found that in cell lines containing inducible versions of alleles encoding the Pro72 and Arg72 variants, and in cells with endogenous p53, the Arg72 variant induced much greater levels of apoptosis than the Pro72 variant. The higher induction of apoptosis by the Arg72 allele results from the increased localization of p53 Arg72 to the mitochondria, which is accompanied by the release of cytochrome $c$ into the cytosol (56). Although further studies are required, differences in the mitochondrial localization of the isoforms may also indicate that the p53 codon 72 SNP affects the ability of p53 to regulate mitochondrial respiration and other metabolic factors (7). Oseki et al (57) showed that these two polymorphic variants differed particularly within the $\mathrm{N}$-terminal region and consequently, they differ in post-translational modifications at this portion. The Arg72 variant shows significantly enhanced phosphorylation at Ser-6 and Ser-20 compared with the Pro72 variant.

Allelic expression associations. We investigated whether the expression of the Pro/Arg alleles of p53 in CRC correlates with cancer behavior and progression. In studies evaluating genetic polymorphisms and cancer, typically only the association with cancer risk is investigated. However, the relationship between polymorphisms and clinicopathological characteristics of the tumor must be elucidated to enable understanding of the tumor pathogenesis and the tumor course.

Our data revealed that there was a high number of tumors expressing Arg72 in the CRC cohort although our results also showed that the expression of the Arg72 allele may exert a protective effect in this population. The expression of the Pro72 allele in CRC tissues may confer a poorer prognosis since expression of this allele was associated with tumor recurrence. Individuals who were Arg72 allele expressers presented a low number of cancer recurrences, lower grade tumors, expanding tumor borders in the majority of the cases and less frequent TP53 mutations.

The relationship between gender and the SNP showed an apparent advantage for women as fewer tumors expressed the Pro72 allele in women. A common environmental source of DNA damage is cigarette smoke, which contains many mutagenic compounds. If p53 protects cells from DNA damage caused by exposure to these mutagens, the degree of protection should vary with the strength and nature of the p53 response. Thus, individuals with a weaker p53 response may be less capable of responding appropriately to cigarette smoke, which in turn will affect the ability to promote an apoptotic function (58). Indeed, epidemiological evidence reveals an association between this SNP and cigarette smoking in lung and bladder cancer patients $(58,59)$. Thus, one possible explanation for our finding is that men typically initiate smoking earlier and smoke more frequently than women $(60,61)$. These findings were replicated in the present study (64.3\% of smokers were men) although we did not find a statistically significant correlation between smoking, gender and the expression of a specific allele. Furthermore, it is important to note that data of this type of habit are derived from self-reported 'yes or no' questionnaires, which may underestimate the true extent of smoking (62).

Several studies have indicated that individual susceptibility factors, including DNA repair capacity, metabolic capacity and variation in genes involved in these processes, may modulate the genotoxicity of xenobiotics $(63,64)$. Hanova et al (65) showed a possible relationship between styrene exposure, DNA damage and the transcript levels of TP53.

Tumor-host interaction at the invasive front of colorectal cancer represents a critical interface where tumor progression and tumor cell dissemination arise. The expanding tumor border, identified as presenting margins reasonably well-circumscribed, is often associated with a well-developed inflammatory infiltrate $(66,67)$. In contrast, the infiltrative tumor border is characterized by widespread dissection of normal tissue structures with a loss in the clear boundary between tumor and host tissues. The infiltrating tumor border configuration promotes progression and dissemination of tumor cells by penetrating the vascular and lymphatic vessels $(66,67)$. Studies have revealed that the infiltrative pattern of growth is an adverse prognostic factor and may predict local recurrence (68), whereas the expanding pattern was related with improved survival (67), which is consistent with our results.

The p53 pathway is critical in mediating the response of commonly used cancer therapies. There is evidence that the TP53 gene has functional SNPs that affect p53 signaling, thus, possibly altering cancer risk and clinical outcome (69). How the functional p53 SNPs interact with known cancer risk factors and therapeutics remains to be answered. The present study provides evidence for the protective effect of Arg72 expression on the requirement for postoperative adjuvant chemoradiotherapy.

Adjuvant therapy for colorectal cancer forms an essential component of an effective treatment strategy. Initially, adjuvant chemotherapy for colorectal cancer was delivered in the post-operative setting following 'curative' surgery to destroy any residual or micrometastatic disease. Today, the effects of chemotherapy for colorectal cancer include delaying and possibly preventing recurrences following 'curative' surgery, downsizing incurable disease in the pre-operative setting and significantly expanding the median survival in the advanced metastatic setting (70). Despite the large number of factors involved in predicting clinical outcome in patients with colorectal cancer, the histologic stage at surgical diagnosis remains the most important prognostic variable (71). Thus, the selection of appropriate patients to receive adjuvant therapy has been based on their risk of recurrence after surgery only and on disease variables known to adversely affect prognosis, and the selection of systemic agents has been typically based on antitumor activity in patients with advanced disease of similar histology (72).

In particular, 5-fluorouracil (5-FU) is widely used in the treatment of a range of cancers and has demonstrated the largest impact on CRC. TP53 can be activated by 5-FU through more than one mechanism including incorporation of fluorouridine triphosphate into RNA, fluorodeoxyuridine triphosphate into DNA and inhibition of thymidylate synthase with resultant DNA damage (73). TP53 status expectedly appears to have predictive value for the survival of $\mathrm{CRC}$ patients receiving 5-FU chemotherapy (74).

One study suggest that cells from individuals that carry the Pro72 allele may undergo less apoptosis in response to DNA 
damage-inducing therapies when compared with individuals carrying the Arg72 allele. This effect has been suggested to be caused by reduced transcriptional activation of apoptotic effectors (75). In this study, Arg72 expression in presence of chemotherapeutic treatment was shown to induce up to 8-fold more apoptosis than the Pro72 with chemotherapeutics. Studies using p53-inducible isogenic cell lines also noted the greater apoptotic potential of the Arg72 both in the presence (75) and absence $(76,77)$ of chemotherapeutics. Patients, homozygote for the Arg72 allele, with breast or lung cancers have been shown to survive and respond more favorably to chemotherapy and radiotherapy (78-80). Further studies of p53 variants could help to define patient populations by their abilities to respond to stress, suppress tumor formation and respond to DNA damaging therapies (69).

In the present study, we showed that $54.5 \%$ of individuals harbor a pathogenic TP53 mutation. The total number of mutations found in this population is consistent with the literature. Petitjean et al (81) stated that TP53 appeared to be mutated in $\sim 50 \%$ of cases in the majority of human tumors. The simultaneous presence of Arg72 allele in the mutated form of TP53 may serve as a predictor of enhanced tumor development due to inactivation of p73. On the other hand, Arg72 allele over wild-type background may potentially increase apoptotic ability (74). A modifier effect of this SNP has been also reported in germline TP53 mutation carriers, where Arg72 was found to be associated with an earlier age at the initial cancer diagnosis (82).

In most studies, this SNP has been identified by amplifying the exon 4 followed by digestion using the AccII restriction enzyme. However, partial digestion of the Arg72 homozygote leads to the same pattern as that derived from a heterozygote, causing erroneous conclusions. In the present study, analyses were conducted using direct sequencing, considered the gold standard for mutation/SNP detection. The method used here is appropriate for determining the quantity of $\mathrm{C}$ or $\mathrm{G}$ nucleotides in RNA samples, as described by Siddique et al (13).

Although we have not used more robust techniques for quantifying allelic expression, the mRNA sequencing of a gene allows for the direct verification of which relation exists between the alleles being expressed and tumor characteristics.

The discrepancies between the present study and others are most likely due to differences in population stratification and the methods used to ascertain the polymorphism. Further studies using larger samples and a more detailed analysis of genetic variations within TP53 are required to examine the role of Pro/Arg alleles in carcinogenesis and to determine whether the proposed association is in linkage disequilibrium with other alleles.

In summary, the data presented here demonstrated that there is a strong correlation between expression of the $\mathrm{p} 53$ Pro allele and the aggressiveness of CRC. Thus, we propose that the expression status, rather than the conventionally analyzed genomic status, of p53 variants should be used in studies searching for associations between exonic SNPs and cancers.

Allelic variation of gene expression is of particular interest due to its potential contribution to variation in heritable traits. Therefore, understanding the degree of, structure of, and patterns of variations in gene expression is of central importance to determine its role in the pathogenesis of CRC.

\section{Acknowledgements}

The present study was supported by the 'Fundação de Amparo à Pesquisa do Estado de São Paulo' - FAPESP (grant no. 2008/01241-3). The investigators thank the study participants and the collaborators who contributed to this research.

\section{References}

1. Tang NP, Wu YM, Wang B, et al: Systematic review and metaanalysis of the association between P53 codon 72 polymorphism and colorectal cancer. Eur J Surg Oncol 36: 431-438, 2010.

2. Valentin MD, da Silva FC, dos Santos EM, et al: Characterization of germline mutations of MLH1 and MSH2 in unrelated South American suspected Lynch syndrome individuals. Fam Cancer 10: 641-647, 2011.

3. da Silva FC, de Oliveira LP, Santos EM, et al: Frequency of extracolonic tumors in Brazilian families with Lynch syndrome: analysis of a hereditary colorectal cancer institutional registry. Fam Cancer 9: 563-570, 2010.

4. Stadler ZK, Vijai J, Thom P, et al: Genome-wide association studies of cancer predisposition. Hematol Oncol Clin North Am 24: 973-996, 2010.

5. Fearon ER and Vogelstein B: A genetic model for colorectal tumorigenesis. Cell 61: 759-767, 1990.

6. Hollstein $M$ and Hainaut P: Massively regulated genes: the example of TP53. J Pathol 220: 164-173, 2010.

7. Shi H, Tan SJ, Zhong H, et al: Winter temperature and UV are tightly linked to genetic changes in the p53 tumor suppressor pathway in Eastern Asia. Am J Hum Genet 84: 534-541, 2009.

8. Mammano E, Belluco C, Bonafé M, et al: Association of p53 polymorphisms and colorectal cancer: modulation of risk and progression. Eur J Surg Oncol 35: 415-419, 2009.

9. The International HapMap Consortium: The International HapMap Project. Nature 426: 789-796, 2003.

10. Marin MC, Jost CA, Brooks LA, et al: A common polymorphism acts as an intragenic modifier of mutant $\mathrm{p} 53$ behaviour. Nat Genet 25: 47-54, 2000.

11. Millau JF, Bastien N and Drouin R: P53 transcriptional activities: a general overview and some thoughts. Mutat Res 681: 118-133, 2009.

12. Hu Z, Li X, Yuan R, et al: Three common TP53 polymorphisms in susceptibility to breast cancer, evidence from meta-analysis. Breast Cancer Res Treat 120: 705-714, 2010.

13. Siddique MM, Balram C, Fiszer-Maliszewska L, et al: Evidence for selective expression of the p53 codon 72 polymorphs: implications in cancer development. Cancer Epidemiol Biomarkers Prev 14: 2245-2252, 2005.

14. Song HR, Kweon SS, Kim HN, et al: p53 codon 72 polymorphism in patients with gastric and colorectal cancer in a Korean population. Gastric Cancer 14: 242-248, 2011.

15. Cañas M, Morán Y, Camargo ME, et al: TP53 codon 72 polymorphism and gastric cancer risk: a case-control study in individuals from the central-western region of Venezuela. Invest Clin 50: 153-161, 2009 (In Spanish).

16. Rogounovitch TI, Saenko VA, Ashizawa K, et al: TP53 codon 72 polymorphism in radiation-associated human papillary thyroid cancer. Oncol Rep 15: 949-956, 2006.

17. Granja F, Morari J, Morari EC, et al: Proline homozygosity in codon 72 of p53 is a factor of susceptibility for thyroid cancer. Cancer Lett 210: 151-157, 2004.

18. Piao JM, Kim HN, Song HR, et al: p53 codon 72 polymorphism and the risk of lung cancer in a Korean population. Lung Cancer 73: 264-267, 2011.

19. Dai S, Mao C, Jiang L, et al: P53 polymorphism and lung cancer susceptibility: a pooled analysis of 32 case-control studies. Hum Genet 125: 633-638, 2009.

20. Rosenthal AN, Ryan A, Hopster D, et al: p53 codon 72 polymorphism in vulval cancer and vulval intraepithelial neoplasia. Br J Cancer 83: 1287-1290, 2000.

21. Lin HY, Huang CH, Yu TJ, et al: p53 codon 72 polymorphism as a progression index for bladder cancer. Oncol Rep 27: 1193-1199, 2012.

22. Li DB, Wei X, Jiang LH, et al: Meta-analysis of epidemiological studies of association of P53 codon 72 polymorphism with bladder cancer. Genet Mol Res 9: 1599-1605, 2010. 
23. Sousa H, Santos AM, Pinto D, et al: Is there a biological plausability for p53 codon 72 polymorphism influence on cervical cancer development? Acta Med Port 24: 127-134, 2011.

24. Klug SJ, Ressing M, Koenig J, et al: TP53 codon 72 polymorphism and cervical cancer: a pooled analysis of individual data from 49 studies. Lancet Oncol 10: 772-784, 2009.

25. Li MS, Liu JL, Wu Y, et al: Meta-analysis demonstrates no association between p53 codon 72 polymorphism and prostate cancer risk. Genet Mol Res 10: 2924-2933, 2011.

26. Zhu Y, Wang J, He Q, et al: Association of p53 codon 72 polymorphism with prostate cancer: a meta-analysis. Mol Biol Rep 38: 1603-1607, 2011.

27. Tang W, He X, Chan Y, et al: Lack of association between $\mathrm{p} 53$ codon 72 polymorphism and endometrial cancer: a meta-analysis. Cancer Epidemiol 36: 153-157, 2012.

28. Zubor P, Stanclova A, Kajo K, et al: The p53 codon 72 exon 4 BstUI polymorphism and endometrial cancer in Caucasian women. Oncology 76: 173-183, 2009.

29. Suresh K, Chandirasekar R, Kumar BL, et al: No association between the Trp53 codon 72 polymorphism and head and neck cancer: a case-control study in a South Indian population. Asian Pac J Cancer Prev 11: 1749-1753, 2010.

30. Mojtahedi Z, Hashemi SB, Khademi B, et al: p53 codon 72 polymorphism association with head and neck squamous cell carcinoma. Braz J Otorhinolaryngol 76: 316-320, 2010.

31. Själander A, Birgander R, Athlin L, et al: P53 germ line haplotypes associated with increased risk for colorectal cancer. Carcinogenesis 16: 1461-1464, 1995.

32. Gemignani F, Moreno V, Landi S, et al: A TP53 polymorphism is associated with increased risk of colorectal cancer and with reduced levels of TP53 mRNA. Oncogene 23: 1954-1956, 2004.

33. Goodman JE, Mechanic LE, Luke BT, et al: Exploring SNP-SNP interactions and colon cancer risk using polymorphism interaction analysis. Int J Cancer 118: 1790-1797, 2006

34. Pérez LO, Abba MC, Dulout FN, et al: Evaluation of p53 codon 72 polymorphism in adenocarcinomas of the colon and rectum in La Plata, Argentina. World J Gastroenterol 12: 1426-1429, 2006

35. Zhu ZZ, Wang AZ, Jia HR, et al: Association of the TP53 codon 72 polymorphism with colorectal cancer in a Chinese population. Jpn J Clin Oncol 37: 385-390, 2007.

36. Dakouras A, Nikiteas N, Papadakis E, et al: p53Arg72 homozygosity and its increased incidence in left-sided sporadic colorectal adenocarcinomas, in a Greek-Caucasian population. Anticancer Res 28: 1039-1043, 2008.

37. Koushik A, Tranah GJ, Ma J, et al: p53 Arg72Pro polymorphism and risk of colorectal adenoma and cancer. Int J Cancer 119 1863-1868, 2006.

38. Tan XL, Nieters A, Hoffmeister M, et al: Genetic polymorphisms in TP53, nonsteroidal anti-inflammatory drugs and the risk of colorectal cancer: evidence for gene-environment interaction? Pharmacogenet Genomics 17: 639-645, 2007.

39. Hase K, Shatney C, Johnson D, et al: Prognostic value of tumor 'budding' in patients with colorectal cancer. Dis Colon Rectum 36: 627-635, 1993

40. López I, Oliveira PL, Tucci P, et al: Different mutation profiles associated to P53 accumulation in colorectal cancer. Gene 499: 81-87, 2012.

41. Goldstein DB: The importance of synthetic associations will only be resolved empirically. PLoS Biol 9: e1001008, 2011.

42. Anderson CA, Soranzo N, Zeggini E, et al: Synthetic associations are unlikely to account for many common disease genome-wide association signals. PLoS Biol 9: e1000580, 2011.

43. Wray NR, Purcell SM and Visscher PM: Synthetic associations created by rare variants do not explain most GWAS results. PLoS Biol 9: e1000579, 2011

44. Orozco G, Barrett JC and Zeggini E: Synthetic associations in the context of genome-wide association scan signals. Hum Mol Genet 19: 137-144, 2010.

45. Shields R: Common disease: are causative alleles common or rare? PLoS Biol 9: e1001009, 2011.

46. Ritchie MD: Using biological knowledge to uncover the mystery in the search for epistasis in genome-wide association studies. Ann Hum Genet 75: 172-182, 2011.

47. Dickson SP, Wang K, Krantz I, et al: Rare variants create synthetic genome-wide associations. PLoS Biol 8: e1000294, 2010.

48. Yan H, Yuan W, Velculescu VE, et al: Allelic variation in human gene expression. Science 297: 1143, 2002.
49. Bray NJ, Buckland PR, Owen MJ, et al: Cis-acting variation in the expression of a high proportion of genes in human brain. Hum Genet 113: 149-153, 2003.

50. Lo HS, Wang Z, Hu Y, et al: Allelic variation in gene expression is common in the human genome. Genome Res 13: 1855-1862, 2003.

51. Schadt EE, Monks SA, Drake TA, et al: Genetics of gene expression surveyed in maize, mouse and man. Nature 422: 297-302, 2003.

52. Pastinen T, Sladek R, Gurd S, et al: A survey of genetic and epigenetic variation affecting human gene expression. Physiol Genomics 16: 184-193, 2004.

53. Cheung VG, Bruzel A, Burdick JT, et al: Monozygotic twins reveal germline contribution to allelic expression differences. Am J Hum Genet 82: 1357-1360, 2008.

54. Gimelbrant A, Hutchinson JN, Thompson BR, et al: Widespread monoallelic expression on human autosomes. Science 318: 1136-1140, 2007

55. Thomas M, Kalita A, Labrecque S, et al: Two polymorphic variants of wild-type p53 differ biochemically and biologically. Mol Cell Biol 19: 1092-1100, 1999.

56. Dumont P, Leu JI, Della Pietra AC III, et al: The codon 72 polymorphic variants of $\mathrm{p} 53$ have markedly different apoptotic potential. Nat Genet 33: 357-365, 2003.

57. Ozeki C, Sawai Y, Shibata T, et al: Cancer susceptibility polymorphism of p53 at codon 72 affects phosphorylation and degradation of p53 protein. J Biol Chem 286: 18251-18260, 2011.

58. Hancox RJ, Poulton R, Welch D, et al: Accelerated decline in lung function in cigarette smokers is associated with TP53/MDM2 polymorphisms. Hum Genet 126: 559-565, 2009.

59. Pandith AA, Shah ZA, Khan NP, et al: Role of TP53 Arg72Pro polymorphism in urinary bladder cancer predisposition and predictive impact of proline related genotype in advanced tumors in an ethnic Kashmiri population. Cancer Genet Cytogenet 203: 263-268, 2010

60. Tobacco Free Initiative (TFI): WHO report on the global tobacco epidemic, 2011: warning about the dangers of tobacco. World Health Organization, 2011. Available at http://www.who.int/ tobacco/global_report/2011/en/.

61. Marqueta A, Nerín I, Jiménez-Muro A, et al: Predictors of outcome of a smoking cessation treatment by gender. Gac Sanit 27: 23-31, 2012 (In Spanish).

62. Hiscock R, Bauld L, Amos A, et al: Socioeconomic status and smoking: a review. Ann NY Acad Sci 1248: 107-123, 2012.

63. Norppa H: Cytogenetic biomarkers and genetic polymorphisms. Toxicol Lett 149: 309-334, 2004.

64. Vodicka P, Kumar R, Stetina R, et al: Genetic polymorphisms in DNA repair genes and possible links with DNA repair rates, chromosomal aberrations and single-strand breaks in DNA. Carcinogenesis 25: 757-763, 2004.

65. Hanova M, Vodickova L, Vaclavikova R, et al: DNA damage, DNA repair rates and mRNA expression levels of cell cycle genes (TP53, p21 $1^{C D K N I A}, B C L 2$ and $B A X$ ) with respect to occupational exposure to styrene. Carcinogenesis 32: 74-79, 2011.

66. Jass JR, Love SB and Northover JM: A new prognostic classification of rectal cancer. Lancet 1: 1303-1306, 1987.

67. Zlobec I, Baker K, Minoo P, et al: Tumor border configuration added to TNM staging better stratifies stage II colorectal cancer patients into prognostic subgroups. Cancer 115: 4021-4029, 2009.

68. Zlobec I, Terracciano LM and Lugli A: Local recurrence in mismatch repair-proficient colon cancer predicted by an infiltrative tumor border and lack of $\mathrm{CD}^{+}$tumor-infiltrating lymphocytes. Clin Cancer Res 14: 3792-3797, 2008.

69. Grochola LF, Zeron-Medina J, Mériaux S, et al: Single-nucleotide polymorphisms in the p53 signaling pathway. Cold Spring Harb Perspect Biol 2: a001032, 2010.

70. Wilkinson NW: Adjuvant chemotherapy for colorectal cancernew perspectives for effective treatment. US Gastroenterol Hepatol Rev 1: 91-93, 2007.

71. Casillas S, Pelley RJ and Milsom JW: Adjuvant therapy for colorectal cancer: present and future perspectives. Dis Colon Rectum 40: 977-992, 1997.

72. Fuchs CS and Mayer RJ: Adjuvant chemotherapy for colon and rectal cancer. Semin Radiat Oncol 3: 29-41, 1993.

73. Longley DB, Harkin DP and Johnston PG: 5-fluorouracil: mechanisms of action and clinical strategies. Nat Rev Cancer 3 : 330-338, 2003

74. Naccarati A, Polakova V, Pardini B, et al: Mutations and polymorphisms in TP53 gene: an overview on the role in colorectal cancer. Mutagenesis 27: 211-218, 2012. 
75. Sullivan A, Syed N, Gasco M, et al: Polymorphism in wild-type p53 modulates response to chemotherapy in vitro and in vivo. Oncogene 23: 3328-3337, 2004.

76. Pim D and Banks L: p53 polymorphic variants at codon 72 exert different effects on cell cycle progression. Int $\mathrm{J}$ Cancer 108 196-199, 2004.

77. Bergamaschi D, Samuels Y, Sullivan A, et al: iASPP preferentially binds p53 proline-rich region and modulates apoptotic function of codon 72-polymorphic p53. Nat Genet 38: 1133-1141, 2006.

78. Nelson HH, Wilkojmen M, Marsit CJ, et al: TP53 mutation, allelism and survival in non-small cell lung cancer. Carcinogenesis 26: 1770-1773, 2005.

79. Tommiska J, Eerola H, Heinonen M, et al: Breast cancer patients with p53 Pro72 homozygous genotype have a poorer survival. Clin Cancer Res 11: 5098-5103, 2005.
80. Xu Y, Yao L, Ouyang T, et al: p53 codon 72 polymorphism predicts the pathologic response to neoadjuvant chemotherapy in patients with breast cancer. Clin Cancer Res 11: 7328-7333, 2005.

81. Petitjean A, Mathe E, Kato S, et al: Impact of mutant p53 functional properties on TP53 mutation patterns and tumor phenotype: lessons from recent developments in the IARC TP53 database. Hum Mutat 28: 622-629, 2007.

82. Bougeard G, Baert-Desurmont S, Tournier I, et al: Impact of the MDM2 SNP309 and p53 Arg72Pro polymorphism on age of tumour onset in Li-Fraumeni syndrome. J Med Genet 43: 531-533, 2006. 